\title{
Genetic introgression among differentiated clades is lower among clades exhibiting different parity modes
}

\section{This article has been corrected since Advance Online Publication and a correction is also printed in this issue}

\author{
J. L. Horreo ${ }^{1}$ - M. C. Breedveld ${ }^{2}$ D. Lindtke ${ }^{3} \cdot$ B. Heulin ${ }^{4}$ Y. Surget-Groba ${ }^{5}$ P. S. Fitze ${ }^{1}$
}

Received: 15 October 2018 / Revised: 19 December 2018 / Accepted: 20 January 2019 / Published online: 4 March 2019

(c) The Genetics Society 2019

\begin{abstract}
Mechanisms leading to sympatric speciation are diverse and may build up reproductive isolation. Reproductive isolation among differentiated clades may exist due to genetic incompatibilities, sexual selection, differences in parity mode, reduced post-zygotic survival or reproductive success of hybrids. Here, we test whether differences in parity mode lead to reproductive isolation by investigating introgression in Zootoca vivipara, a lizard species exhibiting oviparous and viviparous reproduction. We measured introgression in transects spanning different viviparous clades, different oviparous subclades, transects containing oviparous and viviparous clades, and transects within the same subclade (control transects). Introgression in transects spanning oviparous and viviparous clades was one order of magnitude smaller than transects spanning the same reproductive mode and no statistical differences existed between transects spanning the same reproductive mode and control transects. Among types of transects, no significant differences existed in genetic and geographic distances, nor number of detected alleles. Moreover, hybrids were detected in all types of transects, showing that parity mode alone does not necessarily lead to complete reproductive isolation, which suggests that reinforcement may play an important role. The evolution of different parity modes together with reinforcement may thus promote reproductive isolation and rapid speciation, potentially explaining why only six of the almost 40,000 vertebrates belonging to groups consisting of viviparous and oviparous species exhibit bimodal reproduction.
\end{abstract}

\section{Introduction}

Strong genetic structuring of geographically close populations may exist due to physical and climatic barriers

Supplementary information The online version of this article (https:// doi.org/10.1038/s41437-019-0201-7) contains supplementary material, which is available to authorized users.

P. S. Fitze

patrick.fitze@mncn.csic.es

1 Department of Biodiversity and Evolutionary Biology, Museo Nacional de Ciencias Naturales (MNCN-CSIC), Madrid, Spain

2 Animal Ecology, University of Potsdam, Potsdam, Germany

3 Department of Biological Sciences, University of Calgary, Calgary, AB, Canada

4 Station Biologique, CNRS UMR 6553, Paimpont, France

5 Institut des Sciences de la Fôret tempérée, Université du Québec en Outaouais, Ripon, QC, Canada
(Allendorf et al. 2012), reproductive isolation (Boughman 2001), or due to recent secondary contact of genetically differentiated populations (Kvist et al. 2002). Reproductive isolation may exist due to pre- and post-zygotic isolation. Prezygotic isolation can be caused by sexual selection and reproductive incompatibility, while post-zygotic isolation may arise due to reduced viability or fitness of hybrids, i.e. outbreeding depression (Ridley 2004). Lower fitness of hybrids favours the evolution of reinforcement, i.e. assortative mating leading to increased prezygotic isolation (Harrison 1993). Moreover, reinforcement can cause reproductive character displacement, i.e. stronger discrimination against individuals belonging to another population/species in individuals living in sympatry compared to individuals living in allopatry (Wasserman and Koepfer 1977; Pfennig and Pfennig 2012). Reproductive incompatibility leading to pre-zygotic isolation in sympatry can arise due to mechanical isolation, temporal isolation, or behavioural isolation. Post-zygotic isolation can arise due to non-viable zygotes, reduced survival during the zygote and 
the subsequent life stages, infertility of hybrids, reduced reproductive success of hybrids, sexual selection against hybrids (O'rr and Presgraves 2000), or gametic incompatibility, e.g. chromosomal rearrangements (Faria and Navarro 2010). While non-viability of zygotes usually originates from gametic incompatibility (Faria and Navarro 2010), reduced survival during the zygote stage may result from differences among populations/species in uterine anatomy, the fit between the hybrids' requirements during the embryonic stages and the uterine characteristics of the mother, and differences in egg or embryonic retention among females belonging to different taxa. Reduced survival during the zygote stage might promote post-zygotic isolation between taxa exhibiting different reproductive modes. In oviparous reptiles, females retain eggs for a short time, uteri lack or exhibit less developed structures for intrauterine gas and nutrient exchange, and eggs are frequently calcified (Griffith et al. 2015), while viviparous females retain eggs for a much longer time, exhibit placentation, and eggs are uncalcified (Griffith et al. 2015). Consequently, a mismatch between the embryonic requirements and the mother's characteristics may lead to strong, postzygotic isolation. Nevertheless, studies on the Eurasian common lizard (Zootoca vivipara), one of the few reptile species exhibiting oviparous and viviparous reproduction, are contradictory and do not allow understanding whether parity mode may lead to strong postzygotic isolation (Arrayago et al. 1996; Lindtke et al. 2010; Cornetti et al. 2015a, b).

The Eurasian common lizard is the most widely distributed terrestrial reptile in the world (Takeuchi et al. 2014). It consists of six clearly distinct genetic clades, four viviparous (clades $\mathrm{C}, \mathrm{D}, \mathrm{E}$, and $\mathrm{F}$ ) and two oviparous clades (clades A and B), and at least 13 subclades (see Horreo et al. (2018); Fig. 1, for the geographic distribution of the clades/ subclades). Females of two clades (A and F) exhibit $2 N=$ 36 macro-chromosomes, while in the other clades, females exhibit $2 N=35$ macro-chromosomes (Odierna et al. 2001, 2004). The chromosomal reduction stems from a fusion of the ancestral $\mathrm{W}$ chromosome with an autosome, giving rise to a $\mathrm{Z}_{1} \mathrm{Z}_{2} \mathrm{~W}$ sex-chromosome system (Odierna et al. 2001). In contrast to females, males of all clades exhibit $2 N=36$ macro-chromosomes (Odierna et al. 2001, 2004). Numerous secondary contacts among clades and subclades have been described across its natural distribution (Lindtke et al. 2010; Mila et al. 2013; Cornetti et al. 2015a, b; Horreo et al. 2018). One study concluded that hybridisation among the oviparous subclade A1 and the viviparous subclade E1 is possible, since putative hybrids with intermediate developmental traits were detected (Lindtke et al. 2010). Another study ran hybridisation experiments between the viviparous subclade E1 and the oviparous subclades B3 or B4 and concluded that no important reproductive isolation exists (Arrayago et al.
1996). In contrast to these studies, no genetic introgression (i.e. reproductive isolation) among the oviparous subclade A1 and the viviparous subclade E1 was found in a contact zone located in Italy (Cornetti et al. 2015a). Finally, within clade $\mathrm{B}$, relevant genetic introgression exists among oviparous subclades B4 and B2, and most likely as well among B3 and B2 (Mila et al. 2013). The genetic studies suggest little reproductive isolation among oviparous subclades (Mila et al. 2013), and that reproductive isolation among viviparous and oviparous clades is large (Cornetti et al. 2015a, b, 2017), which is in line with the idea that differences in parity mode and/or chromosomal rearrangements (Faria and Navarro 2010) may lead to strong postzygotic isolation. In contrast, experimental studies in captivity and morphological observations suggest that differences in parity mode may not necessarily lead to strong postzygotic isolation (Arrayago et al. 1996; Lindtke et al. 2010). In the captivity study, individuals were unable to choose among viviparous and oviparous mates (Arrayago et al. 1996) and females of both clades exhibited $2 N=35$ macrosomes (Odierna et al. 2001), while in the morphological study conducted in a natural contact zone, lizards were able to choose among viviparous and oviparous mates and in one of the involved clades (A) females exhibit $2 N=36$ and in the other clade (E) $2 N=35$ macrosomes (Odierna et al. 2001; Lindtke et al. 2010), potentially leading to reproductive incompatibility (Faria and Navarro 2010). However, reproductive isolation due to differences in chromosome numbers among male and female $Z$. vivipara is unlikely, because in clades $\mathrm{B}, \mathrm{C}, \mathrm{D}$, and $\mathrm{E}$ females exhibit a different number of chromosomes $(2 N=35)$ while males exhibit $2 N=36$ (Kupriyanova et al. 2008).

Here, we test whether differences in reproductive mode may lead to reproductive isolation by analysing introgression of 34 microsatellites (Horreo et al. 2017) in several contact zones between clades/subclades of Z. vivipara. We compare transects spanning contact zones of oviparous and viviparous clades to transects spanning contact zones of the same reproductive mode belonging to different genetic clades/subclades (i.e. contact zones among viviparous clades, and contact zones among oviparous subclades). We also determined introgression in transects consisting of populations belonging to the same subclade, to provide a baseline measure for introgression among populations where genetic admixture should be easy due to the absence of genetic divergence and differences in reproductive mode. Since in many species introgression is affected by isolation by distance (IBD; Hardy and Vekemans 1999), we tested whether differences in introgression might be explained by the minimum distance between sampled populations belonging to different clades/ subclades. Moreover, reproductive isolation may depend on the age since divergence and thus, introgression might be lower among clades which diverged earlier than among clades which diverged more recently. We therefore tested whether 
differences in introgression might be explained by the age of the most recent common ancestor (MRCA).

We predict that, first, if differences in parity mode promote reproductive isolation, no or less introgression will exist in transects spanning populations belonging to viviparous and oviparous clades, compared to transects spanning populations belonging to either viviparous or oviparous clades/subclades. Second, if IBD and/or age since divergence account for between-transect differences in introgression, we predict that the minimum distance between sampled populations belonging to different clades/ subclades and/or the age of their MRCA will be significantly correlated with the amount of introgression.

\section{Materials and methods}

Eleven Z. vivipara transects were designed across Europe. The transects consisted of two to six populations (mean \pm SE: $3.36 \pm 0.39$ populations) that belong to two different subclades (Fig. 1; Suppl. Mat. Table S1 provides the phylogenetic studies showing to which clade/subclade the populations belong) and exhibit the same (oviparous/oviparous and viviparous/viviparous) or a different (oviparous/ viviparous) reproductive mode (Table 1). Three transects included two different oviparous subclades (subclades B2 and B4; located in Andorra, France, and Spain), three included different viviparous subclades (subclades D1 and E2 or subclades D3 and E2; located in Hungary, Slovakia, Ukraine, Poland, and Belorussia), three included one oviparous (A1) and one viviparous (E1) subclade (located in Italy, Switzerland, France, and Austria), and two included populations belonging to the same oviparous subclade (B2; Table 1, Fig. 1). The latter were included as a control, and they allow understanding whether reproductive isolation among different subclades differs from the degree of reproductive isolation of populations belonging to the same subclade. We used up to 20 samples per population for the analyses (Suppl. Mat. Table S1). In populations from which we had more than 20 samples, 20 samples were randomly chosen. In total, 377 individuals were analysed for this study (Table 1; Suppl. Mat. Table S1).

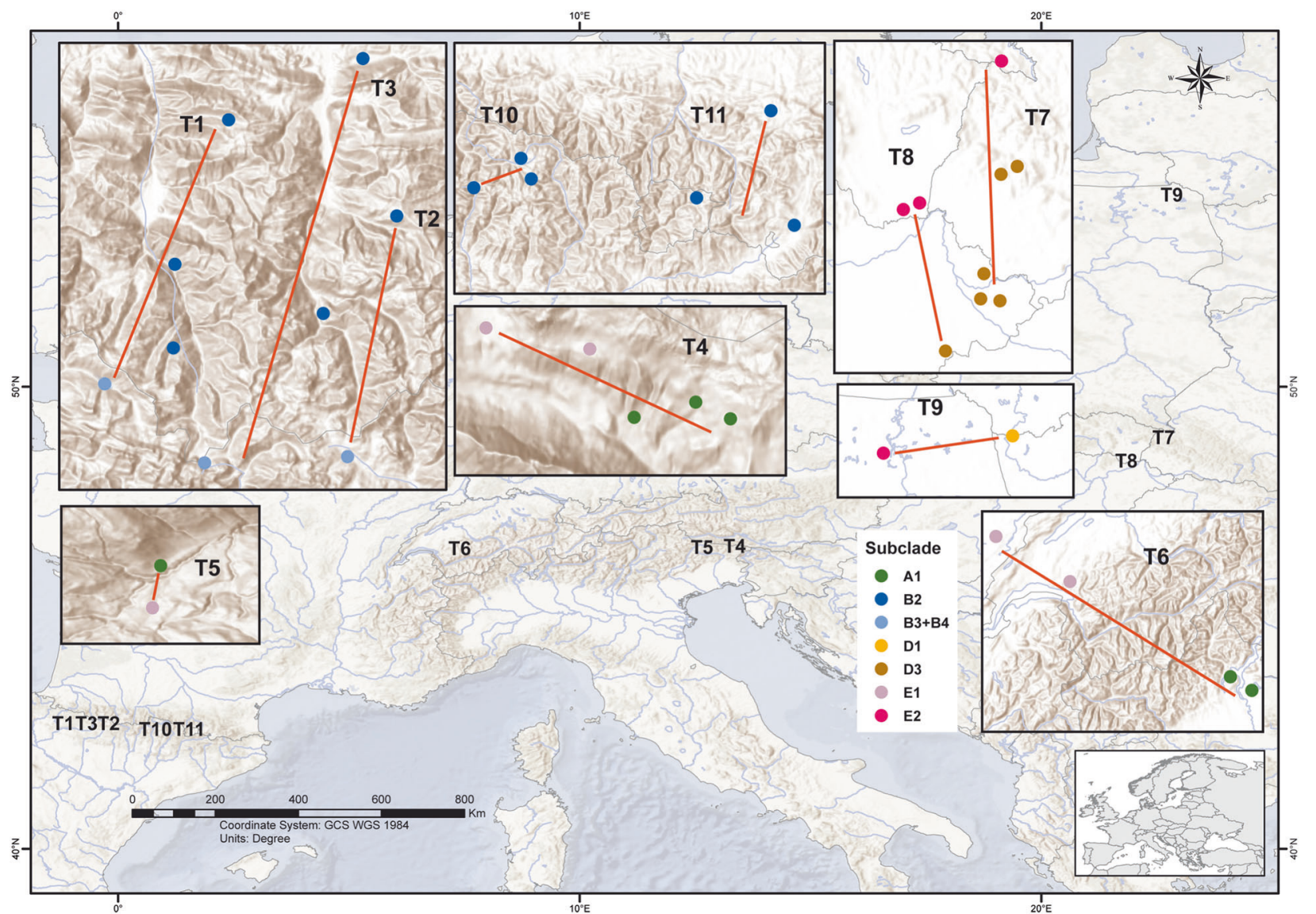

Fig. 1 Geographic location of the 11 studied transects. Colours on the central map reflect the approximate geographic distribution of the $Z$. vivipara subclades. Subclades A1, B2, B3, B4 exhibit oviparous reproduction and all other subclades viviparous reproduction. Zooms of geographic areas are given to provide details of the transects' location. T1-T11 correspond to the transect number given in Tables 1 and 2 . Transects 4,5 , and 6 correspond to transects containing viviparous and oviparous subclades, transects 7,8 , and 9 consist of only viviparous subclades, and all other transects consist of only oviparous subclades 
Table 1 Genetic variability of the studied Zootoca vivipara samples and attribution to two subclades by STRUCTURE

\begin{tabular}{|c|c|c|c|c|c|c|c|c|}
\hline \# & Subclade & Mode & Country & $N$ & $\mathrm{Na}$ & Eff_Na & Ho & $\mathrm{He}$ \\
\hline \multirow[t]{2}{*}{1} & B2 & OVI & France & 26 & 8.82 & 5.43 & 0.72 & 0.82 \\
\hline & B4 & OVI & Spain & 11 & 5.81 & 3.99 & 0.73 & 0.77 \\
\hline \multirow[t]{2}{*}{2} & B2 & OVI & France & 20 & 8.09 & 5.36 & 0.68 & 0.82 \\
\hline & B4 & OVI & Spain & 20 & 5.65 & 3.29 & 0.60 & 0.64 \\
\hline \multirow[t]{2}{*}{3} & B2 & OVI & France & 26 & 9.00 & 5.72 & 0.66 & 0.82 \\
\hline & B4 & OVI & Spain & 13 & 5.79 & 4.07 & 0.66 & 0.76 \\
\hline \multirow[t]{2}{*}{4} & A1 & OVI & Italy & 19 & 5.59 & 3.58 & 0.52 & 0.66 \\
\hline & E1 & VIVI & Italy & 20 & 5.97 & 3.85 & 0.53 & 0.70 \\
\hline \multirow[t]{2}{*}{5} & A1 & OVI & Austria & 20 & 5.53 & 3.43 & 0.47 & 0.68 \\
\hline & E1 & VIVI & Austria & 18 & 5.59 & 3.49 & 0.52 & 0.71 \\
\hline \multirow[t]{2}{*}{6} & A1 & OVI & Italy & 19 & 5.21 & 3.57 & 0.45 & 0.63 \\
\hline & E1 & VIVI & $\begin{array}{l}\text { France, } \\
\text { Switzerland }\end{array}$ & 20 & 6.16 & 4.02 & 0.54 & 0.74 \\
\hline \multirow[t]{2}{*}{7} & E2 & VIVI & Poland & 10 & 6.21 & 4.46 & 0.55 & 0.80 \\
\hline & D3 & VIVI & $\begin{array}{l}\text { Ukraine, } \\
\text { Hungary }\end{array}$ & 22 & 9.91 & 6.64 & 0.60 & 0.84 \\
\hline \multirow[t]{2}{*}{8} & E2 & VIVI & Slovakia & 11 & 5.91 & 4.29 & 0.60 & 0.78 \\
\hline & D3 & VIVI & Hungary & 7 & 5.27 & 3.97 & 0.63 & 0.75 \\
\hline \multirow[t]{2}{*}{9} & D1 & VIVI & Belorussia & 10 & 4.48 & 3.31 & 0.55 & 0.71 \\
\hline & E2 & VIVI & Poland & 6 & 4.60 & 3.49 & 0.61 & 0.76 \\
\hline \multirow[t]{2}{*}{10} & B2 & OVI & Spain & 29 & 6.42 & 3.49 & 0.55 & 0.64 \\
\hline & B2 & OVI & Spain & 10 & 4.75 & 3.13 & 0.52 & 0.63 \\
\hline \multirow[t]{2}{*}{11} & B2 & OVI & $\begin{array}{l}\text { Andorra, } \\
\text { France }\end{array}$ & 20 & 5.73 & 3.98 & 0.59 & 0.73 \\
\hline & B2 & OVI & France & 20 & 6.21 & 3.93 & 0.60 & 0.72 \\
\hline
\end{tabular}

$\mathrm{N}$ sample size, $\mathrm{Na}$ allele number, Eff_Na effective allele number, $\mathrm{Ho}$ observed heterozygosity, $\mathrm{He}$ expected heterozygosity per transect and subclade, \# transect number, Mode: reproductive mode (OVIoviparous, VIVI-viviparous)

DNA was extracted with a commercial kit following published protocols (Horreo et al. 2015). A highly variable microsatellite loci panel, consisting of 34 microsatellites (nZV1-nZV34), was amplified in all samples using seven multiplexes (Horreo et al. 2017). Genotyping was done with GeneMapper v.4.0 (Applied Biosystems, CA, USA) and allele binning with Tandem v.1.09 software (Matschiner and Salzburger 2009). The genetic variability (effective number of alleles per locus: Eff_Na, observed and expected heterozygosity: $\mathrm{Ho}$ and $\mathrm{He}$ ) of the populations was determined using GENODIVE (Merimans and Van Tienderen 2004). The same software was also employed to calculate pairwise fixation indices $\left(\mathrm{F}_{\mathrm{ST}}\right)$ among populations, in order to unravel genetic differentiation.

The presence of genetic introgression within transects was assessed with two Bayesian clustering methods. First, the software STRUCTURE v.2.3.4 (Pritchard et al. 2000) generates posterior assignment probabilities ('admixture coefficients') of individuals to each of a given number of clusters $(N=2$ subclades, in our case). STRUCTURE analyses were run for each transect independently and with the following settings: two clusters $(K=2)$, ten independent runs, 1 million repetitions (10\% burn-in), and admixture model with correlated allele frequencies.
Thereafter, the number of hybrids within a transect was quantified. To this end, individuals were classified as being or not being hybrids using a threshold on the estimated admixture coefficient. Individuals with a proportion of admixture $\geq 3 \%$ were considered to be hybrids, following Horreo et al. (2014). In our case, $\geq 3 \%$ corresponds to introgression in $\geq 1$ loci. Thereafter, a population was attributed to a given subclade if $>50 \%$ of the microsatellites of $>50 \%$ of the individuals sampled in this population belonged to this subclade. Second, NewHybrids v.1.1 (Anderson and Thompson 2002) was used to estimate for each individual of a transect the posterior probability that an individual was pure, a first/second-generation hybrid $\left(\mathrm{F}_{1} / \mathrm{F}_{2}\right.$ respectively), or a backcross between the two genetic clusters of a given transect. Only individuals with posterior probability $\geq 0.98$ were taken into account.

Within transects, the average introgression was calculated per population by averaging the admixture coefficients given by STRUCTURE. Average admixture coefficients were transformed (transformation: $x^{0.05}$ ) to meet the normality assumption and weighted least square regression was run using $\mathrm{JMP}^{\circledR}$ 11.2.0. Average introgression was modelled as dependent variable, reproductive mode comparison (oviparous-oviparous, viviparous-viviparous, or oviparous-viviparous) as fixed factor, and transect as random factor. Within transects, the smallest air-line distance between two populations belonging to different subclades (hereafter referred to as 'minimum distance') was determined and the age of the MRCA of the two subclades was derived from Horreo et al. (2018). Both variables were used as covariates to test whether differences among transects in the minimum distance or age since divergence significantly affect average introgression. Differences among transects in the number of alleles $(\mathrm{Na})$, effective number of alleles (Eff_Na), observed heterozygosity (Ho), and expected heterozygosity $(\mathrm{He})$ were analysed based on data presented in Table 1 using mixed-model ANOVAs with transect as random factor and subclade, reproductive mode, or transect type as fixed factors. Normality of the residuals was tested and met in all presented models. Significance levels are two-tailed with a 0.05 significance level.

\section{Results}

The analyses on genetic variability within transects (Table 1) showed that the number of alleles within transects ranged between 4.48 (transect 9, subclade D1) and 9.91 (transect 7, subclade D3), and the observed heterozygosity between 0.45 (transects 6, subclades A1) and 0.73 (transect 1, subclade B4). No significant differences in genetic variability 
(number and effective number of alleles per locus, observed and expected heterozygosity) existed between oviparous and viviparous populations (all ANOVA $P$-values $>0.05$, Table 1). There were no significant differences in the number (Na) and effective number (Eff_Na) of alleles per locus between types of transects (all $P>0.05$ ). Significant differences existed among types of transects in observed (Ho; $F_{2,18.13}=23.534, P<0.001$ ) and expected heterozygosity $\left(\mathrm{He} ; F_{2,18.33}=5.800, P=0.011\right)$. In both cases, heterozygosity was lowest in transects consisting of both, viviparous and oviparous populations (post-hoc contrasts: $P<0.05)$ and no significant differences existed among transects consisting only of viviparous or only of oviparous populations $(P>0.05)$. There existed significant difference among subclades in the observed heterozygosity $\left(F_{6,15}=3.923, \quad P=0.015\right)$, but not in the number and effective number of alleles per locus and the expected heterozygosity (all $P>0.05$ ). Posthoc contrasts showed that subclade A1 exhibited lower observed heterozygosity than subclades B2, B4, D3, and E2 (all $P \leq 0.03$ ), and E1 exhibited lower heterozygosity than B2 and B4, while no significant differences existed among the other subclades (all $P \geq 0.05)$. $\mathrm{F}_{\mathrm{ST}}$ were statistically significant $(P<0.01)$ among all population pairs (including controls), indicating that all populations were genetically different from each other.

Within transects, STRUCTURE assigned individuals to two genetic groups (Suppl. Mat. Fig. S1). STRUCTURE analyses unravelled admixture in all transects (Table 2). The average proportion of genetic introgression ranged between $0.002(\mathrm{SE}=0.001)$ in transect 6 (oviparous/viviparous comparison) and $0.160(\mathrm{SE}=0.071)$ in transect 9 (viviparous/viviparous comparison). Mean introgression values were $0.036(\mathrm{SE}=0.013)$ in transects consisting of oviparous subclades $\mathrm{B} 2$ and $\mathrm{B} 4,0.005(\mathrm{SE}=0.002)$ in transects consisting of the oviparous subclade $\mathrm{A} 1$ and the viviparous subclade $\mathrm{E} 1,0.074(\mathrm{SE}=0.024)$ in transects consisting of the viviparous subclades D1 or D3 and E2, and 0.020 $(\mathrm{SE}=0.005)$ in the control transects.

STRUCTURE unravelled 46 hybrid individuals $(12.2 \%$ of the individuals exhibited $\geq 3 \%$ of introgression), and the proportion of hybrids ranged between $0 \%$ (transects 6 and 8 ) and $43.2 \%$ (transect 1; Table 2). In transects with different reproductive modes (transects 4-6), only 2 hybrids were found (Table 2) and the remaining 44 hybrids stem from transects consisting of one reproductive mode. The proportion of individuals with high levels of introgression (>20\% introgression) was remarkable and all types of transects consisted of individuals with high levels of genomic introgression (Table 2). NewHybrids unravelled 104 hybrids (Table 2) and the proportion of hybrids ranged between 0\% (transects 4-6) and 89.2\% (transect 1; Table 2). In transects with different reproductive modes no hybrids were detected and in all other transects at least one hybrid was detected. Eighty-two hybrids were $\mathrm{F}_{2}$ and 22 were backcrosses (Table 2).

There were significant differences in the average admixture coefficient between types of transects (oviparous/ viviparous, oviparous/oviparous, and viviparous/viviparous; $F_{2,27.5}=3.478, P=0.045$; Fig. 2). Posthoc contrasts unravelled that the admixture coefficients were significantly lower in transects consisting of oviparous and viviparous
Table 2 Genetic introgression per transect

\begin{tabular}{|c|c|c|c|c|c|c|c|}
\hline \multirow{2}{*}{$\begin{array}{l}\text { Transect } \\
1\end{array}$} & \multicolumn{2}{|c|}{$\begin{array}{l}\text { Subclades (parity } \\
\text { mode) }\end{array}$} & \multirow{2}{*}{$\frac{\text { Dist. }}{6.9}$} & \multirow{2}{*}{$\frac{\text { Introgression }(\mathrm{SE})}{0.080(0.018)}$} & \multirow{2}{*}{$\begin{array}{l}\text { Hybrids } \\
16(0.432)\end{array}$} & \multirow{2}{*}{$\frac{H 20}{6}$} & \multirow{2}{*}{$\frac{\mathrm{NH}}{33 \mathrm{~F}_{2}}$} \\
\hline & B2 (o) & B4 (o) & & & & & \\
\hline 2 & B2 (o) & B4 (o) & 21.2 & $0.016(0.001)$ & $3(0.075)$ & 1 & $16 \mathrm{Bx}$ \\
\hline 3 & B2 (o) & B4 (o) & 16.5 & $0.015(0.003)$ & $4(0.102)$ & 0 & $16 \mathrm{~F}_{2}$ \\
\hline 4 & A1 (o) & E1 (v) & 1.0 & $0.010(0.007)$ & $1(0.026)$ & 1 & 0 \\
\hline 5 & A1 (o) & E1 (v) & 2.2 & $0.003(0.001)$ & $1(0.026)$ & 0 & 0 \\
\hline 6 & A1 (o) & E1 (v) & 142.3 & $0.002(0.001)$ & $0(0.000)$ & 0 & 0 \\
\hline 7 & D3 (v) & E2 (v) & 53.9 & $0.069(0.033)$ & $6(0.187)$ & 4 & $14 \mathrm{~F}_{2}$ \\
\hline 8 & D3 (v) & E2 (v) & 75.8 & $0.005(0.001)$ & $0(0.000)$ & 0 & $5 \mathrm{Bx}$ \\
\hline 9 & D1 (v) & E2 (v) & 165.6 & $0.160(0.071)$ & $5(0.312)$ & 4 & $2 \mathrm{~F}_{2}$ \\
\hline 10 & B2 (o) & B2 (o) & 18.7 & $0.021(0.008)$ & $4(0.103)$ & 1 & $1 \mathrm{Bx}$ \\
\hline 11 & B2 (o) & B2 (o) & 38.4 & $0.019(0.007)$ & $6(0.150)$ & 1 & $17 \mathrm{~F}_{2}$ \\
\hline
\end{tabular}

Shown are the involved subclades (according to Horreo et al. (2018)), parity mode (o: oviparous; v: viviparous) and the average proportion of the genome introgressed (Introgression) from the other subclade (standard error, SE, is given in brackets). Dist.: minimum distance within transects between sampled populations that belong to different subclades (in $\mathrm{km}$ ); Hybrids: number and proportion of hybrids (proportion is shown in brackets) and number of individuals exhibiting $\geq 20 \%$ introgression (abbreviated as: H20) according to STRUCTURE analyses (Suppl. Mat. Fig. S1), and NH: number and type of hybrids according to NewHybrids analyses: $F_{1}$ first-generation hybrids; $F_{2}$ second-generation hybrids; $B x$ backcrosses 


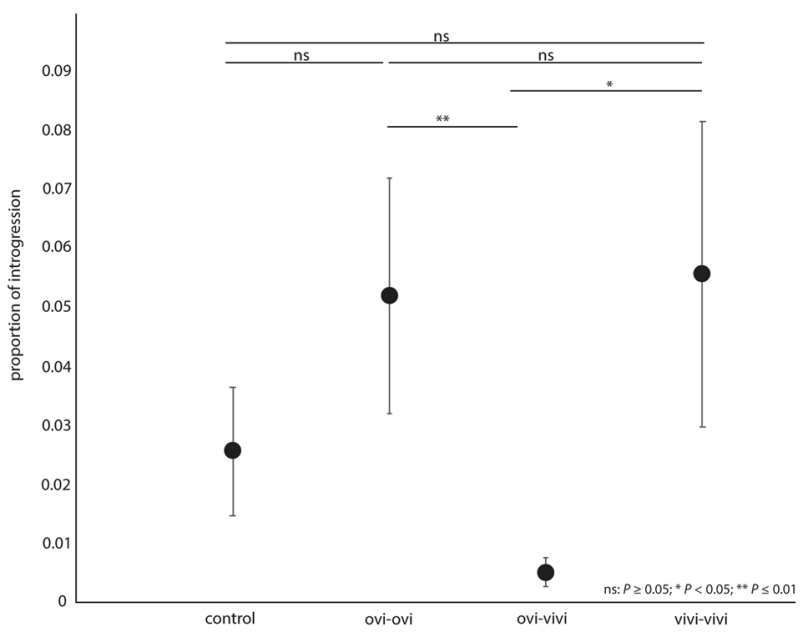

Fig. 2 Proportion of introgression in the four types of transects: oviparous-oviparous (ovi-ovi), viviparous-viviparous (vivi-vivi), oviparous-viviparous (ovi-vivi), and control transects consisting of oviparous populations belonging to the same subclade (control). Means \pm SE are given and horizontal lines above the SE indicate pairwise post-hoc contrasts among types of transects

subclades (mean \pm SE: $0.005 \pm 0.002$ ) than in transects consisting of the same reproductive mode (oviparous: $0.041 \pm 0.013, \quad F_{1,33.13}=6.91, \quad P=0.013 ; \quad$ viviparous: $0.056 \pm 0.026, F_{1,30.51}=4.30, P=0.047$; Fig. 2). No significant differences in admixture coefficients existed among purely oviparous and purely viviparous transects $\left(F_{1,25.17}=\right.$ $0.125, P=0.727)$ and among control transects and purely oviparous transects $\left(F_{1,8.954}=0.612, P=0.454\right)$. Average admixture coefficients were not significantly correlated with the per transect minimum distance between sampled populations belonging to different subclades $\left(F_{1,33}=0.019\right.$, $P=0.892)$, nor with the age since divergence $\left(F_{1,32}=\right.$ $0.655, P=0.424)$. There were significant differences between types of transects in the number of hybrids unravelled by STRUCTURE $\left(F_{2,8}=5.955, P=0.026\right)$ and by NewHybrids $\left(F_{1,8}=4.905, P=0.041\right)$. Posthoc-contrasts showed that transects consisting of oviparous and viviparous clades had significantly less hybrids than transects consisting only of oviparous or only of viviparous clades/ subclades (STRUCTURE: $F_{1,8}=10.319, P=0.012$; NewHybrids: $\left.F_{1,8}=9.740, P=0.014\right)$. No significant differences existed between transects consisting only of viviparous subclades and transects consisting only of oviparous subclades (both methods: $P>0.05$ ) and between transects consisting of only oviparous subclades and the control transects (both methods: $P \geq 0.2$ ).

\section{Discussion}

Different factors can produce strong genetic structuring of geographically close populations, including physical and climatic barriers (Allendorf et al. 2012), reproductive isolation (Boughman 2001), and secondary contact of differentiated populations. Here, we investigated whether differences in reproductive mode (oviparity vs viviparity) may lead to reproductive isolation. Introgression was significantly lower in transects consisting of viviparous and oviparous clades (Fig. 2), while no significant differences in introgression existed among transects consisting only of viviparous or only of oviparous clades/subclades and control transects (all $P \geq 0.4$ ). Heterozygosity was lowest in transects consisting of viviparous and oviparous populations and no significant differences existed among transects consisting only of viviparous or only of oviparous populations, potentially due to reduced hybridisation or lower inbreeding in subclade A1. In all types of transects, STRUCTURE detected admixed individuals (Table 2), while NewHybrids did not detect hybrids in transects containing oviparous and viviparous populations (Table 2).

The results are in line with our first prediction, that differences in parity mode and/or chromosomal morphology may promote reproductive isolation, as admixture coefficients in transects consisting of oviparous and viviparous clades were very small (mean genetic introgression per population $=0.005, \mathrm{SD}=0.008$ ) and significantly different from admixture coefficients among subclades exhibiting the same reproductive mode and those among populations belonging to the same subclade (i.e. control transects; Fig. 2). In transects consisting of oviparous and viviparous clades, STRUCTURE unravelled $1.7 \%$ of individuals as hybrids ( $\geq 3 \%$ of genetic introgression; Horreo et al. 2014) and NewHybrids unravelled no hybrids. By contrast, transects consisting only of viviparous or oviparous subclades exhibited significantly higher admixture coefficients (viviparous: mean genetic introgression per population $=$ $0.056, \mathrm{SE}=0.086$; oviparous: mean genetic introgression per population $=0.04, \mathrm{SE}=0.05$ ) and significantly more hybrids (viviparous: 11 individuals $-16.67 \%$ according to STRUCTURE, and 21 individuals-31.8\% according to NewHybrids; oviparous: 23 individuals $-19.83 \%$ and 65 individuals-56\%) than the transects among viviparous and oviparous clades. Introgression detected in transects including subclades with different reproductive modes was one order of magnitude lower than introgression detected in transects including subclades exhibiting the same reproductive mode.

The existence of significant introgression between subclades B2 and B4 and a relevant number of hybrids is in line with findings of previous studies (Mila et al. 2013), that unravelled (i) mito-nuclear discordance, which is a clear signal of hybridisation among subclades (Mila et al. 2013), and (ii) gene flow between subclades (Horreo et al. 2019). There existed also important introgression among the viviparous clades D1 and E1 and a relevant number of hybrids 
(Table 2, Fig. 2). This points to no or little reproductive isolation between subclades exhibiting the same reproductive mode. This result together with the strong genetic differentiation among subclades and clades (Horreo et al. 2018) suggests that genetic diversification happened in allopatry and that during secondary contact the genetic structuring may get weaker.

STRUCTURE analyses point to genetic introgression in transects consisting of viviparous and oviparous clades (Table 2), namely in transects 4 and 5. Interestingly, while Lindtke et al. (2010) detected hybrids in a narrow contact zone (locality 3, Fig. 1 in Lindtke et al. (2010); note that this core contact zone was not included in this study), the here detected hybrid exhibited $5.2 \%$ of introgression and stems from locality 1 (Fig. 1 in Lindtke et al. (2010)), where no hybrids have been detected previously, which is in line with the results of NewHybrids. In this contact zone, the presence of hybrids confirmed by intermediate reproductive characteristics (developmental stage, eggshell thickness, eggs surface structure, birth weight; Lindtke et al. 2010) is in line with previous studies indicating that reproductive isolation between oviparous and viviparous clades of $Z$. vivipara is not complete (Arrayago et al. 1996; Lindtke et al. 2010).

The low amount of introgression in the transects including oviparous and viviparous populations might be caused by different chromosome numbers that may lead to alignment problems during meiosis (Cornetti et al. 2015a). However, in this case crosses between a viviparous female $(2 N=35)$ and a viviparous or an oviparous male (all males are $2 N=36$ ) would be affected, but not necessarily crosses between an oviparous female of clade $\mathrm{A}(2 N=36)$ and a viviparous or an oviparous male $(2 N=36)$. Given that in clades $\mathrm{B}, \mathrm{C}, \mathrm{D}$, and $\mathrm{E}$ no reproductive incompatibilities exist (females exhibit $2 N=35$, and males $2 N=36$ ), and given that reproductive success of crosses between mates with the same number of chromosomes, but differences in parity mode was reduced (clades B and E; Arrayago et al. 1996), differences in chromosome numbers are insufficient to explain why introgression was one order of magnitude lower in transects consisting of different parity modes (Fig. 2).

The existence of hybrids (Lindtke et al. 2010) and the presence of introgression in transects 4 and 5 (Table 2) show that prezygotic isolation due to differences in parity mode (prediction 1) is incomplete, which is in line with findings of (Arrayago et al. 1996). However, the low frequency of hybrids in these transects detected by STRUCTURE analyses and by Lindtke et al. (2010), and the absence of hybrids in Cornetti et al.'s (2015a) study and in the NewHybrids analyses, suggest that mechanisms other than differences in chromosome number or parity by itself may account for reproductive isolation. For example, outbreeding depression (i.e. reduced survival and/or reduced reproductive success of hybrids resulting from hybridisation between viviparous and oviparous subclades; Arrayago et al. 1996) may explain the scarcity of hybrids. Moreover, Z. vivipara exhibits strong mate preferences (Fitze et al. 2005, 2008, 2010; Fitze and Le Galliard 2008; San-Jose et al. 2014; Breedveld and Fitze 2015, 2016; Breedveld et al. 2017) and the oviparous subclade A1 and the viviparous subclade E1 exhibit small morphological differences (Lindtke et al. 2010; Rodriguez-Prieto et al. 2017). Thus, reinforcement by means of assortative mating (Ridley 2004) may also explain the low frequency of hybrids (Boughman 2001).

Within transects, admixture coefficients were not correlated with the geographic minimum distance among populations belonging to different subclades. Genetic admixture was high in transects 7 and 9 (viviparous-viviparous), despite the long distances separating populations belonging to different clades (Table 1), while in transect 5 (oviparous-viviparous) admixture was very low, despite the very short geographic distance. In addition, all studied populations were genetically different (all pairwise $\mathrm{F}_{\mathrm{ST}}$ $P$-values $<0.01)$, no significant differences existed in allele numbers ( $\mathrm{Na}$ and Eff_Na) among populations belonging to different clades/subclades within transects, and the age of their MRCA (derived from Horreo et al. (2018)) was not correlated with the admixture coefficient $\left(F_{1,32}=0.655\right.$, $P=0.424)$. Thus, differences in genetic introgression among different types of transects cannot be explained by geographic distance, age since divergence, nor by differences in the structuring within and between subclades.

In conclusion, our study shows that differences in parity mode do not necessarily lead to incompatibility in reproduction. The low frequency of hybrids between oviparous and viviparous $Z$. vivipara together with previous hybridisation experiments (Arrayago et al. 1996) suggest that the strong reproductive isolation observed between viviparous and oviparous clades (this study and Cornetti et al. (2015a, b, 2017)) might be the result of low hybrid fitness and/or pre-zygotic isolation potentiated by reinforcement. Moreover, the relevant introgression detected in viviparous and oviparous transects and its similarity with introgression detected in control transects is in line with the diversification of clades and subclades in allopatry (Horreo et al. 2018) and subsequent secondary contacts.

Viviparity has evolved several times in vertebrates (Blackburn 1999; Jamieson 2009; Griffith et al. 2015; VeloAntón et al. 2015; Wake 2015), namely in mammals and cartilaginous fishes, teleosts, sauropsids, and amphibians. $20 \%$ of lizard and snakes, $15 \%$ of caecilians, $2 \%$ of teleosts, less than $2 \%$ of the salamanders, and few toads and frogs exhibit viviparous reproduction (Blackburn 1999; Jamieson 2009; Griffith et al. 2015; Velo-Antón et al. 2015; Wake 
2015). The vertebrate groups exhibiting viviparous reproduction contain almost 40,000 described species (IUCN 2018), but only 6 are known to exhibit a bimodal reproductive mode: the lizards Z. vivipara, Lerista bougainvillii, and Saiphos equalis (Smith and Shine 1997; Surget-Groba et al. 2001; Qualls and Shine 2006), the water snake Helicops angulatus (Braz et al. 2016), and the salamanders Salamandra salamandra and Salamandra algira (Velo-Antón et al. 2015). Moreover, in $Z$. vivipara it has been suggested that one oviparous clade (clade A; Z. vivipara carniolica) may actually be a separate species (Cornetti et al. 2015b). The extremely small proportion of species with bimodal reproductive mode is therefore in line with the idea that differences in parity mode may lead to reproductive isolation and thus to rapid speciation, suggesting that bimodal species cannot be maintained over longer evolutionary time scales.

\section{Data availability}

Data available from the Dryad Digital Repository: https:// doi.org/10.5061/dryad.qp7539t.

Acknowledgements J.L.H. was supported by a Spanish MINECO postdoc grant IJCI-2015-23618. D.L. was supported by the German Academic Exchange Service. Project funds were provided by the Swiss National Science Foundation (PPOOP3_128375, PP00P3_152929/1 to P.S.F.) and the Spanish Ministry of Education and Science (CGL200801522, CGL2012-32459, CGL2016-76918 to P.S.F.). A special thank goes to María Luisa Peláez Aller and Teresa Suárez for help with the molecular analyses, Werner Mayer and the Central Research Laboratories of the Natural History Museum Vienna for help with sample collection, and Victoria Gonzalez Cascon (GIS Laboratory of the $\mathrm{MNCN}$ ) who helped elaborating Figure 1.

\section{Compliance with ethical standards}

Conflict of interest The authors declare that they have no conflict of interest.

Publisher's note: Springer Nature remains neutral with regard to jurisdictional claims in published maps and institutional affiliations.

\section{References}

Allendorf FW, Luikart G, Aitken SN (2012) Conservation and the genetics of populations. Wiley-Blackwell, Sussex, UK

Anderson EC, Thompson EA (2002) A model-based method for identifying species hybrids using multilocus genetic data. Genetics 160:1217-1229

Arrayago MJ, Bea A, Heulin B (1996) Hybridization experiment between oviparous and viviparous strains of Lacerta vivipara: a new insight into the evolution of viviparity in reptiles. Herpetologica 52:333-342

Blackburn DG (1999) Are viviparity and egg-guarding evolutionarily labile in squamates? Herpetologica 55:556-573

Boughman JW (2001) Divergent sexual selection enhances reproductive isolation in sticklebacks. Nature 411:944-948. https://doi. org/10.1038/35082064
Braz HB, Scartozzoni RR, Almeida-Santos SM (2016) Reproductive modes of the South American water snakes: a study system for the evolution of viviparity in squamate reptiles. Zool Anz 263:33-44. https://doi.org/10.1016/j.jcz.2016.04.003

Breedveld MC, Fitze PS (2015) A matter of time: delayed mate encounter postpones mating window initiation and reduces the strength of female choosiness. Behav Ecol Sociobiol 69:533-541. https://doi.org/10.1007/s00265-014-1864-y

Breedveld MC, Fitze PS (2016) The timing and interval of mate encounter affects investment during mating. BiolJ Linn Soc 118:610-617. https://doi.org/10.1111/bij.12747

Breedveld MC, San Jose LM, Romero-Diaz C, Roldan ERS, Fitze PS (2017) Mate availability affects the trade-off between producing one or multiple annual clutches. Anim Behav 123:43-51. https:// doi.org/10.1016/j.anbehav.2016.10.025

Cornetti L, Belluardo F, Ghielmi S, Giovine G, Ficetola GF, Bertorelle $\mathrm{G}$ et al. (2015a) Reproductive isolation between oviparous and viviparous lineages of the Eurasian common lizard Zootoca vivipara in a contact zone. Biol J Linn Soc 114:566-573. https:// doi.org/10.1111/bij.12478

Cornetti L, Ficetola GF, Hoban S, Vernesi C (2015b) Genetic and ecological data reveal species boundaries between viviparous and oviparous lizard lineages. Heredity 115:517-526. https://doi.org/ 10.1038/hdy.2015.54

Cornetti L, Griffith OW, Benazzo A, Panziera A, Whittington CM, Thompson MB et al. (2017) Candidate genes involved in the evolution of viviparity: a RAD sequencing experiment in the lizard Zootoca vivipara (Squamata: Lacertidae). Zool J Linn Soc 183:196-207. https://doi.org/10.1093/zoolinnean/zlx069

Faria R, Navarro A (2010) Chromosomal speciation revisited: rearranging theory with pieces of evidence. Trends Ecol Evol 25:660-669. https://doi.org/10.1016/j.tree.2010.07.008

Fitze PS, Cote J, Clobert J (2010) Mating order-dependent female mate choice in the polygynandrous common lizard Lacerta vivipara. Oecologia 162:331-341. https://doi.org/10.1007/s00442009-1463-1

Fitze PS, Cote J, Martínez-Rica JP, Clobert J (2008) Determinants of male fitness: disentangling intra- and inter-sexual selection. J Evol Biol 21:246-255. https://doi.org/10.1111/j.1420-9101.2007. 01447.x

Fitze PS, Le Galiard J-F, Federici P, Richard M, Clobert J (2005) Conflict over multiple-partner mating between males and females of the polygynandrous common lizards. Evolution 59:2451-2459. https://doi.org/10.1554/05-208.1

Fitze PS, Le Galliard JF (2008) Operational sex ratio, sexual conflict and the intensity of sexual selection. Ecol Lett 11:432-439. https://doi.org/10.1111/j.1461-0248.2008.01158.x

Griffith OW, Blackburn DG, Brandley MC, Van Dyke JU, Whittington CM, Thompson MB (2015) Ancestral state reconstructions require biological evidence to test evolutionary hypotheses: a case study examining the evolution of reproductive mode in Squamate reptiles. J Exp Zool B: Mol Dev Evol 324:493-503. https://doi.org/10.1002/jez.b.22614

Hardy OJ, Vekemans X (1999) Isolation by distance in a continuous population: reconciliation between spatial autocorrelation analysis and population genetics models. Heredity 83:145-154. https:// doi.org/10.1046/j.1365-2540.1999.00558.x

Harrison RG (1993) Hybrid zones and the evolutionary process. Oxford University Press, Ithaca, New York, NY

Horreo JL, Machado-Schiaffino G, Griffiths AM, Bright D, Stevens JR, Garcia-Vazquez E (2014) Long-term effects of stock transfers: synergistic introgression of allochthonous genomes in salmonids. J Fish Biol 85:292-306. https://doi.org/10.1111/jfb. 12424

Horreo JL, Peláez ML, Breedveld MB, Suárez T, Urieta M, Fitze PS (2019) Population structure of the oviparous South-West 
European common lizard. Eur J Wild Res 65:11. https://doi.org/ 10.1007/s10344-018-1242-6

Horreo JL, Peláez ML, Fitze PS (2015) Skin sheds as a useful DNA source for lizard conservation. Phyllomedusa 14:73-77. https:// doi.org/10.11606/issn.2316-9079.v14i1p73-77

Horreo JL, Peláez ML, Suárez T, Breedvled MC, Heulin B, SurgetGroba Y et al. (2018) Phylogeography, evolutionary history, and effects of glaciations in a species (Zootoca vivipara) inhabiting multiple biogeographic regions. J Biogeogr 45:1616-1627. https://doi.org/10.1111/jbi.13349

Horreo JL, Peláez ML, Suárez T, Heulin B, Fitze PS (2017) Development of thirty-four new microsatellite loci and multiplexing of seven existing loci for Zootoca vivipara. Phyllomedusa 16:89-96. https://doi.org/10.11606/issn.2316-9079.v16i1p89-96

IUCN - International Union for Conservation of Nature (2018) IUCN Red List of threatened species. Version 2018, IUCN, Gland, Switzerland.

Jamieson BGM (2009) Reproductive biology and phylogeny of fishes (agnathans and bony fishes). Science Publishers, Enfield, NH

Kupriyanova L, Kuksin A, Odierna G (2008) Karyotype, chromosome structure, reproductive modalities of three Southern Eurasian populations of the common lacertid lizard, Zootoca vivipara (Jacquin, 1787). Acta Herpetol 3:99-106. https://doi.org/10. 13128/Acta_Herpetol-2677

Kvist L, Martens J, Higuchi H, Nazarenko AA, Valchuk OP, O'rell M (2002) Evolution and genetic structure of the great tit (Parus major) complex. Proc R Soc B 270:1447-1454. https://doi.org/ 10.1098/rspb.2002.2321

Lindtke D, Mayer W, Böhme W (2010) Identification of a contact zone between oviparous and viviparous common lizards (Zootoca vivipara) in central Europe: reproductive strategies and natural hybridization. Salamandra 46:73-82

Matschiner M, Salzburger W (2009) TANDEM: integrating automated allele binning into genetics and genomics workflows. Bioinformatics 25:1982-1983. https://doi.org/10.1093/bioinformatics/ btp303

Merimans PG, Van Tienderen PH (2004) GENOTYPE and GENODIVE: two programs for the analysis of genetic diversity of asexual organisms. Mol Ecol Notes 4:792-794. https://doi.org/10. 1111/j.1471-8286.2004.00770.x

Mila B, Surget-Groba Y, Heulin B, Gosá A, Fitze PS (2013) Multilocus phylogeography of the common lizard Zootoca vivipara at the Ibero-Pyrenean suture zone reveals lowland barriers and highelevation introgression. BMC Evol Biol 13:192. https://doi.org/ 10.1186/1471-2148-13-192

O'rr GA, Presgraves DC (2000) Speciation by postzygotic isolation: forces, genes and molecules. BioEssays 22:1085-1094. https:// doi.org/10.1002/1521-1878
Odierna G, Aprea G, Capriglione T, Puky M (2004) Chromosomal evidence for the double origin of viviparity in the European common lizard Lacerta (Zootoca) vivipara. Herpetol J 14:157-160

Odierna G, Heulin B, Guillaume CP, Vogrin N, Aprea G, Capriglione $\mathrm{T}$ et al. (2001) Evolutionary and biogeographical implications of the karyological variations in the oviparous and viviparous forms of Lacerta vivipara. Ecography 24:332-340. https://doi.org/10. 1034/j.1600-0587.2001.240311.x

Pfennig DW, Pfennig KS (2012) Evolution's wedge: competition and the origins of diversity. University of California Press, Berkeley, CA

Pritchard JK, Stephens M, Donnelly P (2000) Inference of population structure using multilocus genotype data. Genetics 155:945-959

Qualls CP, Shine R (2006) Lerista bougainvillii, a case study for the evolution of viviparity in reptiles. J Evol Biol 11:63-78. https:// doi.org/10.1046/j.1420-9101.1998.11010063.x

Ridley M (2004) Evolution. Blackwell Publishing, Oxford, UK

Rodriguez-Prieto A, Giovine G, Laddaga L, Ghielmi S, Cornetti L (2017) Very similar, but not identical: morphological taxonomic identification to improve the resoution of fine-scale distribution of Zootoca (vivipara) carniolica. Amphib-Reptil 38:533-539. https://doi.org/10.1163/15685381-00003120

San-Jose LM, Peñalver-Alcázar M, Milá B, Gonzalez-Jimena V, Fitze PS (2014) Cumulative frequency-dependent selective episodes allow for rapid morph cycles and rock-paper-scissors dynamics in species with overlapping generations. Proc R Soc B 281:20140976. https://doi.org/10.1098/rspb.2014.0976

Smith SA, Shine R (1997) Intraspecific variation in reproductive mode within the scincid lizard Saiphos equalis. Aust J Zool 45:435-445

Surget-Groba Y, Heulin B, Guillaume CP, Thorpe RS, Kupriyanova L, Bogrin $\mathrm{N}$ et al. (2001) Intraspecific phylogeography of Lacerta vivipara and the evolution of viviparity. Mol Phylogenet Evol 18:449-459. https://doi.org/10.1006/mpev.2000.0896

Takeuchi H, Zhu GX, Ding L, Tang Y, Ota H, Mori A et al (2014) Taxonomic Validity and Phylogeography of the East Eurasian Natricine Snake, (Berthold, 1859) (Serpentes: Colubridae), as Inferred from Mitochondrial DNA Sequence Data Current Herpetology 33:148-153

Velo-Antón G, Santos X, Sanmartín-Villar I, Cordero-Rivera A, Buckley D (2015) Intraspecific variation in clutch size and maternal investment in pueriparous and larviparous Salamandra salamandra females. Evol Ecol 29:185-204. https://doi.org/10. 1007/s10682-014-9720-0

Wake MH (2015) Fetal adaptations for viviparity in amphibians. J Morphol 276:941-960. https://doi.org/10.1002/jmor.20271

Wasserman M, Koepfer HR (1977) Character displacement for sexual isolation between Drosophila mojavensis and Drosophila arizonensis. Evolution 31:812-823 